\title{
Hybrid HDPE/MCM-41 nanocomposites: Crystalline structure and viscoelastic behaviour
}

\author{
María L. Cerrada ${ }^{\mathrm{a}, *}$, Ernesto Pérez ${ }^{\mathrm{a}}$, João Paulo Lourenço ${ }^{\mathrm{b}}$, João M. Campos ${ }^{\mathrm{c}}$, M. Rosário Ribeiro ${ }^{\mathrm{c}, *}$ \\ a Instituto de Ciencia y Tecnología de Polímeros (CSIC), Juan de la Cierva 3, 28006 Madrid, Spain \\ ${ }^{\mathrm{b}}$ Centro de Investigação em Química do Algarve, Departamento de Química, Bioquímica e Farmácia, Faculdade de Ciências e Tecnologia-Universidade do Algarve, \\ Campus de Gambelas, 8005-139 Faro, Portugal \\ ${ }^{\mathrm{C}}$ Instituto de Ciência e Engenharia de Materiais e Superfícies, Departamento de Engenharia Química e Biológica, Instituto Superior Técnico - Universidade Técnica de Lisboa, \\ Av. Rovisco Pais 1, 1049-001 Lisboa, Portugal
}

\section{A R T I C L E I N F O}

Article history:

Received 20 August 2009

Received in revised form 5 November 2009

Accepted 6 November 2009

Available online 11 November 2009

\section{Keywords:}

Polyethylene/MCM-41 nanocomposites

Crystallinity

Degradability

Stiffness

\begin{abstract}
A B S T R A C T
Polyethylene-based nanocomposites have been prepared by in situ polymerisation of ethylene with mesostructured MCM-41 within a large range of nanofiller concentrations. The structural, thermal and viscoelastic studies have shown that the use of mesoporous MCM-41 as catalyst carrier and its further presence in the final material is an effective route for the successful attainment of nanocomposites. Data shows that minimal changes in crystallinity are observed but crystallites become thicker as MCM- 41 content is raised in the nanocomposites. A confinement effect is found and a delay in the crystallisation process of the macrochains within pores and channels is observed. These novel self-reinforced nanocomposites present an enhanced rigidity, which becomes more important as temperature is raised. Accordingly, they exhibit an improved mechanical performance without varying the final processing temperature since $T_{m}$ is the same for all of the specimens. In agreement with other works, it is confirmed that the MCM-41 acts as promoter for polyethylene degradation, an easier degradability being observed in these nanocomposites.
\end{abstract}

(c) 2009 Elsevier Inc. All rights reserved.

\section{Introduction}

Recent published works have been focused on the use of mesostructured silicas and its aluminated variants (MCM-41, Al-MCM41, SBA-15 and Al-SBA-15) to prepare novel catalysts and applied porous materials with very promising behaviours [1-4]. Studies on metallocene and other transition metal catalysts have been performed, dealing mainly with the effects of support composition, preparation and polymerisation conditions on polymerisation activity [5-10]. These investigations also show that mesostructured silicate materials allow the preparation of Philips catalysts with very high activities in ethylene polymerisation, particularly when using SBA-15 mesoporous silica $[11,12]$.

On the other hand, zeolites and mesoporous materials are particularly interesting to be used as the inorganic phase in the preparation of multicomponent polymeric nanocomposites. They present stable 3D framework structures that may lead to some interesting confinement effects and that can resist to the forces produced by intercalated polymers, which tend to break up the

\footnotetext{
* Corresponding authors. Tel.: +34 915622900; fax: +34 915644853 (M.L. Cerrada), tel.: +351 218417325; fax: +351 218419198 (M.R. Ribeiro).

E-mail addresses: mlcerrada@ictp.csic.es (M.L. Cerrada), rosario@ist.utl.pt (M.R. Ribeiro).
}

inorganic material. There are two primary methods for the preparation of nanocomposites from porous inorganic materials [13]: (i) direct threading of preformed polymer through the inorganic host channels, for soluble and melting polymers, which is usually limited by their size, conformation and diffusion behaviour, and (ii) the in situ polymerisation in the pores and channels of the inorganic hosts. In situ polymerisation gives better filler dispersion than simple melt preparation, particularly at high filler contents, and provides a promising strategy for obtaining nanocomposites with desirable properties. Some recent studies have also shown that zeolites and MCM-41 derivatives are potential candidates to be used as promoters of the catalytic cracking of polyolefins, allowing its conversion at lower temperatures, in gaseous and liquid products that can be used as fine chemicals or fuels [14-16].

In previous works, polyethylene-based nanocomposites were prepared by in situ coordination polymerisation of ethylene with MCM-41 and aluminated MCM-41 (Al-MCM-41) as fillers [9,17]. The route followed took advantage of the unique properties of the MCM-41 material, which was used in a triple role: (i) as carrier for the immobilisation of the polymerisation catalysts and allowing ethylene polymerisation within its pores and channels; (ii) as inorganic nanofiller of the polyethylene matrix formed; and (iii) as promoter for the degradation of the nanocomposite material. A preliminary characterisation of these nanocomposites 
was presented [17]. This work deals with a detailed analysis of these novel nanocomposites from a structural and viscoelastic standpoint. Accordingly, X-ray measurements at wide and small angle regions (WAXS and SAXS, respectively) as well as supplementary DSC experiments have been carried out to evaluate the structural characteristics. In addition, a thorough microhardness evaluation is presented as well as a complete dynamic mechanical thermal analysis (DMTA) performed to examine the mechanical and viscoelastic behaviour of these materials.

\section{Experimental}

\subsection{Preparation of the HDPE/MCM-41 nanocomposite materials}

The detailed procedures used in the preparation of the HDPE/ MCM-41 nanocomposite materials were already published in two previous papers $[9,17]$. In short, a dilute solution of zirconocene catalyst is contacted with a dry sample of mesoporous material during $16 \mathrm{~h}$. An adequate volume of the resulting suspension is then injected into a $250 \mathrm{~cm}^{3}$ reactor already charged with toluene and methylaluminoxane (cocatalyst), connected to the ethylene line. Once the polymerisation is started, the consumption of ethylene is registered by data acquisition in a computer. After $30 \mathrm{~min}$, the reactor content is quenched with acidified methanol and the solid is washed twice with fresh methanol, before drying overnight.

\subsection{Preparation of specimens}

The HDPE/MCM-41( $x$ ) nanocomposites were processed as thick films (around $400 \mu \mathrm{m}$ ) by compression moulding in a Collin press between hot plates at $170{ }^{\circ} \mathrm{C}$, at a pressure of $1.5 \mathrm{MPa}$, for $5 \mathrm{~min}$. Each of the HDPE/MCM-41( $x$ ) specimens was crystallised by a fast quench in cold water after melting in the press.

\subsection{Polymer characterisation}

TEM images were obtained in Hitachi H8100 equipment. Nanocomposite samples were deposited in a $\mathrm{Cu} /$ polymer grid sample holder.

The wide, middle and small angle X-ray synchrotron studies (WAXS, MAXS and SAXS, respectively) were performed in the soft-condensed matter beamline A2 at Hasylab (Hamburg, Germany), working at a wavelength of $0.150 \mathrm{~nm}$. Two different setups were used. In the first one a MAR CCD detector, at a distance of $17 \mathrm{~cm}$ from the sample (which is inside the temperature controller of the beamline) was used for studying the WAXS region. A sample of silver behenate (giving a well-defined diffraction at a spacing of $5.838 \mathrm{~nm}$, and several orders) was used for calibration. A heating rate of $8^{\circ} \mathrm{C} / \mathrm{min}$ was employed, acquiring images every $15 \mathrm{~s}$. In the second setup, the MAR CCD and one linear position-sensitive detector were used simultaneously, the former at $230 \mathrm{~cm}$ from the sample (covering the SAXS region) and the latest at around $17 \mathrm{~cm}$ from the sample and covering the approximate $2 \theta$ range from $11^{\circ}$ to $30^{\circ}$ (WAXS region). This WAXS detector was calibrated with the diffractions of a crystalline PET sample, and the MAR CCD detector, now with the different orders of the long spacing of rattail tendon $(L=65 \mathrm{~nm})$. A heating rate of $8{ }^{\circ} \mathrm{C} / \mathrm{min}$ was used in this case, acquiring frames every $15 \mathrm{~s}$. The two-dimensional X-ray patterns were processed with the FIT2D program of Dr. Hammersley (ESRF) and converted into one-dimensional arrays after normalisation for the intensity of the primary beam and subtraction of the scattering of an empty sample.

The crystalline diffractions and the amorphous component in the WAXS region have been separated with a fitting program, which allows estimating the crystallinity of the samples. The baseline has been taken just as a straight line in the $2 \theta$ range from $10^{\circ}$ to $32^{\circ}$, and no further correction has been applied. The different diffraction peaks were fitted to Voigt functions. The amorphous peak of the different samples was found centred at about $2 \theta=19.7^{\circ}$. The error in the crystallinity determinations is estimated to be \pm 5 units.

Calorimetric analyses were carried out in a Perkin-Elmer DSC7 calorimeter, connected to a cooling system and calibrated with different standards. The sample weights ranged from 5 to $7.5 \mathrm{mg}$. A temperature interval from -50 to $150{ }^{\circ} \mathrm{C}$ has been studied and the used heating rate was $10^{\circ} \mathrm{C} / \mathrm{min}$. For crystallinity determinations, a value of $290 \mathrm{~J} / \mathrm{g}$ has been taken as the enthalpy of fusion of a perfectly crystalline material $[18,19]$.

The decomposition of the nanocomposites was surveyed by thermogravimetry using a TA Instruments TGA Q500 equipment working under an inert atmosphere. The equipment was calibrated according to standard protocols. The sample weights ranged from 4 to $6 \mathrm{mg}$, and the heating rate was $10^{\circ} \mathrm{C} / \mathrm{min}$.

A Vickers indentor attached to a Leitz microhardness tester was used to perform microindentation measurements undertaken at $23^{\circ} \mathrm{C}$. A contact load of $0.98 \mathrm{~N}$ and a contact time of $25 \mathrm{~s}$ were employed. Microhardness, $\mathrm{MH}$, values (in $\mathrm{MPa}$ ) were calculated according to the relationship [20]:

$\mathrm{MH}=2 \sin 68^{\circ} \mathrm{P} / \mathrm{d}^{2}$

where $P$ (in $\mathrm{N}$ ) is the contact load and $d$ (in $\mathrm{mm}$ ) is the diagonal length of the projected indentation area. Diagonals were measured in the reflected light mode within $30 \mathrm{~s}$ of load removal, using a digital eyepiece equipped with a Leitz computer-counter-printer (RZA-DO).

Viscoelastic properties were measured in a Polymer Laboratories MK II dynamic mechanical thermal analyser working in a tensile mode. The complex modulus and the loss tangent for each sample were determined at $1,3,10$ and $30 \mathrm{~Hz}$ over a temperature range from -150 to $130^{\circ} \mathrm{C}$, at a heating rate of $1.5^{\circ} \mathrm{C} / \mathrm{min}$.

\section{Results}

The in situ polymerisation results of zirconocene supported on purely siliceous and aluminated MCM-41 mesoporous material were discussed in previous works [9,17]. In short, the zirconocene catalyst was immobilised on the MCM-41 via a direct impregnation route. Polymerisation activity may vary considerably by changing from a purely siliceous to an aluminated support. Accordingly, different MCM-41-based supports (Table 1) and polymerisation conditions have been carefully selected in order to control the activity level and, consequently, to allow preparing nanocomposite materials with different contents in inorganic nanofillers (from $3 \%$ to $28 \%$ wt.\%, Table 2). As aforementioned, mesoporous MCM-41 acts as catalyst support as well as nanofiller in these materials. The characterisation of these

Table 1

Parameters of the MCM-41 mesoporous materials [9] used as fillers.

\begin{tabular}{lllll}
\hline MCM-41 filler & $\mathrm{Si} / \mathrm{Al}$ & $S_{\mathrm{BET}}\left(\mathrm{m}^{2} / \mathrm{g}\right)$ & $V_{p}\left(\mathrm{~cm}^{3} / \mathrm{g}\right)$ & $D_{p}(\AA)$ \\
\hline MSI & - & 1007 & 0.85 & 33.8 \\
M47 & 47 & 975 & 0.80 & 32.8 \\
M30 & 30 & 1057 & 0.87 & 32.9 \\
M16 & 16 & 1092 & 0.82 & 30.0 \\
\hline
\end{tabular}

$S_{\text {BET: }}$ specific surface area.

$V_{p}$ : specific pore volume.

$D_{p}$ : average pore diameter $\left(D_{p}=4 V_{p} / S_{\mathrm{BET}}\right)$. 
Table 2

HDPE/MCM-41 nanocomposite samples prepared [17].

\begin{tabular}{|c|c|c|c|c|c|c|c|}
\hline \multirow[t]{2}{*}{ Nanocomposite } & \multirow[t]{2}{*}{ Filler } & \multirow[t]{2}{*}{$\mathrm{Cp}_{2} \mathrm{ZrCl}_{2}$ load in filler $\left(10^{-6} \mathrm{~mol} / \mathrm{g}\right)$} & \multirow[t]{2}{*}{ Amount of filler (mg) } & \multirow[t]{2}{*}{$\mathrm{Al} / \mathrm{Zr}$ ratio } & \multirow[t]{2}{*}{ Total yield (mg) } & \multicolumn{2}{|l|}{ MCM-41 contents (wt.\%) } \\
\hline & & & & & & Support (mg)/yield (mg) & TGA \\
\hline HDPE & None & - & - & 500 & 2200 & - & 0 \\
\hline HDPE/MCM-41(3) & М30 & 50 & 40 & 1500 & 1560 & 3 & 3 \\
\hline HDPE/MCM-41(4) & M47 & 50 & 41 & 500 & 950 & 4 & 4 \\
\hline HDPE/MCM-41(6) & M16 & 50 & 41 & 500 & 680 & 6 & 5 \\
\hline HDPE/MCM-41(14) & MSI & 13 & 160 & 1500 & 1160 & 14 & 16 \\
\hline HDPE/MCM-41(23) & MSI & 13 & 166 & 500 & 720 & 23 & 24 \\
\hline HDPE/MCM-41(28) & MSI & 13 & 157 & 500 & 560 & 28 & 33 \\
\hline
\end{tabular}

nanocomposites from a morphological, structural and viscoelastic standpoint is presented in the following sections.

\subsection{Morphological and structural characterisation}

Fig. 1 displays the TEM micrograph found in the HDPE/MCM41(14) hybrid material. It provides information about either particle distribution or size of agglomerates of MCM-41 within the polyethylene matrix. The filler particles are rather uniformly dispersed in the matrix although some aggregates are also observed although their average sizes are at the nanometric scale as seen in this micrograph.

Fig. 2 shows the WAXS profiles at room temperature for the nanocomposites, prepared by in situ supported ethylene polymerisation, as well as for polyethylene synthesised under corresponding homogeneous conditions. It is well known that polyethylene crystallises in an orthorhombic lattice characterised by the two main $\left(\begin{array}{lll}1 & 1 & 0\end{array}\right)$ and $\left(\begin{array}{lll}2 & 0 & 0\end{array}\right)$ diffractions [21,22]. From the analysis of the WAXS patterns it is clear that the location of spacing for these two diffractions is rather constant for the different samples and, consequently, dimensions of crystal lattice are practically unchanged by incorporation of MCM-41 derivatives. The effect of temperature on the initial crystalline lattice developed during the processing, estimated by real-time temperature-variable synchrotron experiments, is depicted in Fig. 3. No significant variations are observed when increasing temperature in the different nanocomposites independently of the nanofiller content. Accordingly, location of the melting temperature, $T_{m}$, is rather similar for all

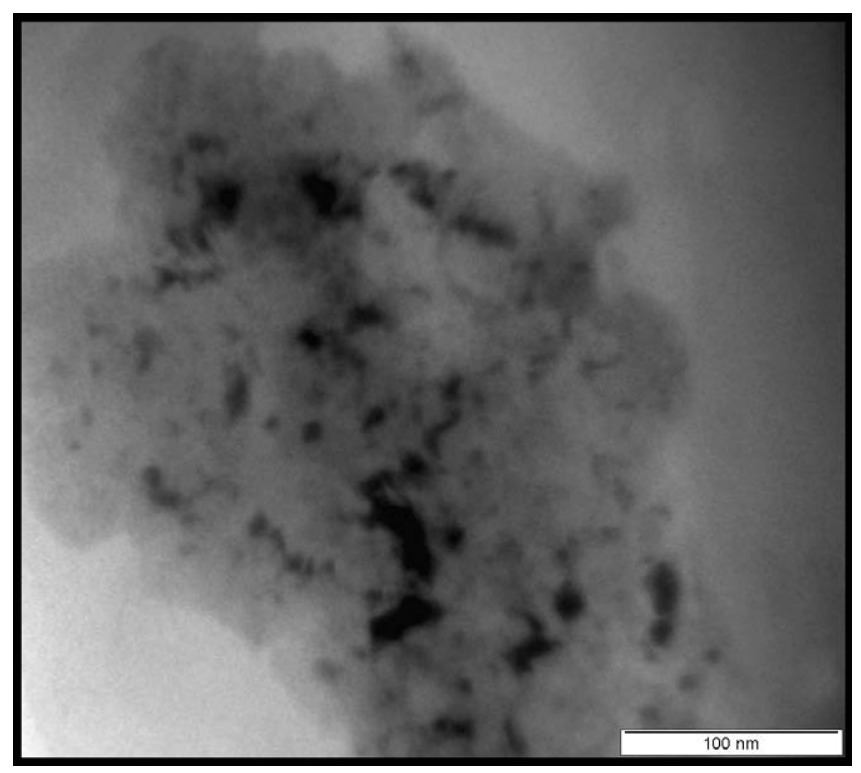

Fig. 1. TEM micrograph of the HDPE/MCM-41(14) nanocomposite.

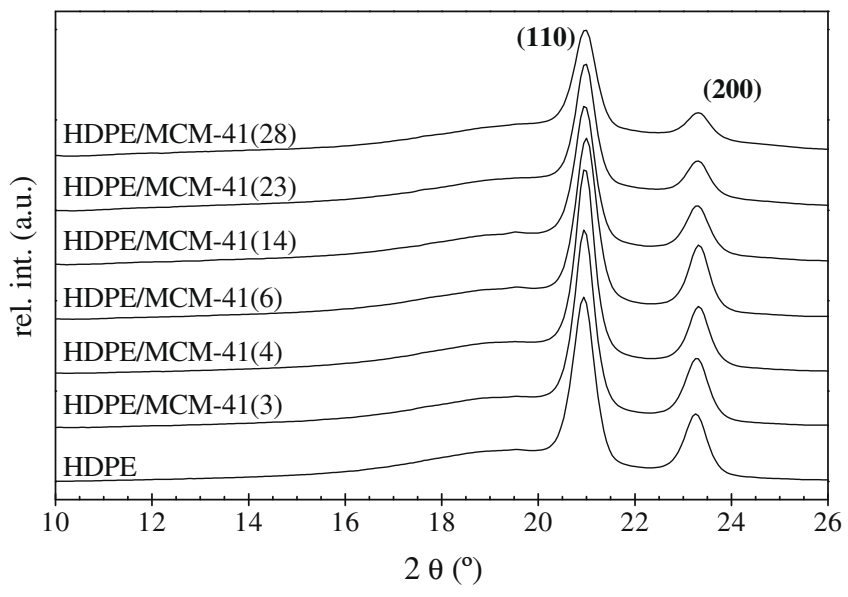

Fig. 2. WAXS diffraction patterns at room temperature for the HDPE homopolymer and the different nanocomposites.

samples, as reported in Table 3. Crystallinity degree can be determined from decomposition of the different WAXS profiles into the crystalline diffractions and amorphous halo (as commented in the Section 2). The values estimated at room temperature are also reported in Table 3, and analogous crystallinity values are found for the different specimens once results are normalised to the actual polyethylene amount at a given nanocomposite.

Patterns at room temperature in the SAXS region are represented in Fig. 4 for HDPE and the nanocomposite samples. This plot clearly shows that the position of the SAXS peak is moved to lower $1 / d$ values, i.e. the long spacing $(L=d)$ increases as MCM-41 content is raised, as reported in Table 3. Nevertheless, for HDPE/ MCM-41(23) and HDPE/MCM-41(28) nanocomposites the peak is located beyond the lower limit of the $1 / d$ scale. These materials were confirmed to be semicrystalline, as observed from WAXS profiles, but their characteristic long spacing, larger than those exhibited in samples with lower filler contents, is not measurable under the experimental conditions used.

Real-time temperature-variable SAXS profiles are presented in Fig. 5 for HDPE and set of three nanocomposites. The patterns show that as the temperature rises, approaching $T_{m}$, the SAXS peak related to long spacing is shifted to lower $1 / d$ values and its intensity is increased. These features are ascribed to the enlargement of crystallite size and thickness with temperature. According to these results, initial small and thin crystallites become larger and thicker. In the case of HDPE, the long spacing increases from 32.5 to $43.8 \mathrm{~nm}$, as depicted in the upper plot of Fig. 6. This enhancement is also seen in the nanocomposites; for instance, long spacing rises from 39.7 to $46.1 \mathrm{~nm}$ in HDPE/MCM-41(14).

The mesoporous structure of MCM-41 leads to the confinement of some polyethylene chains inside its pores and channels. This effect is also evident from the variation of the relative invariant [23] 

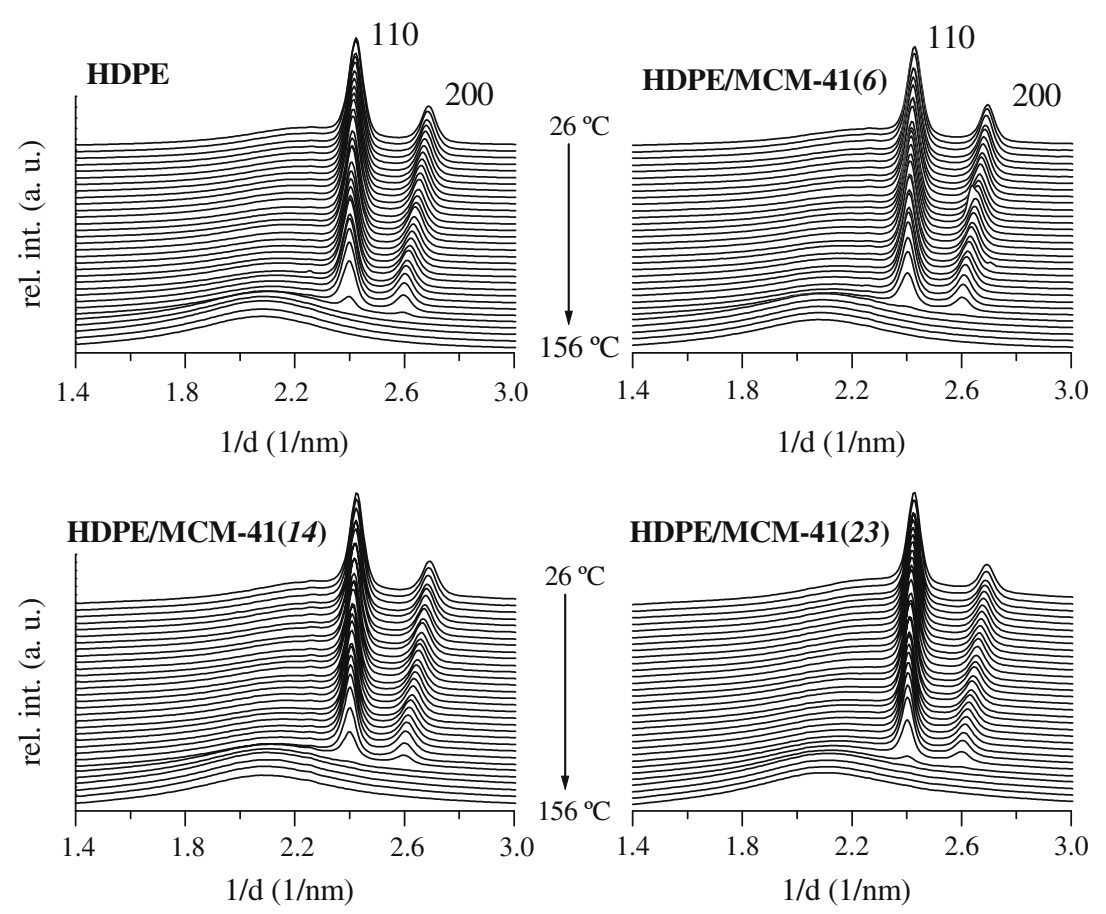

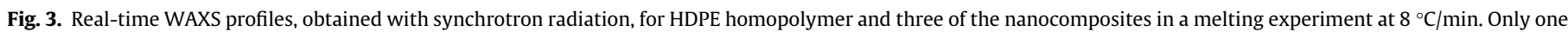
frame every three is plotted, for clarity.

Table 3

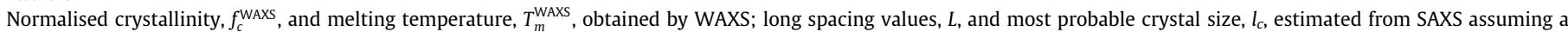

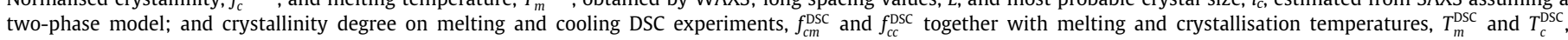
respectively.

\begin{tabular}{|c|c|c|c|c|c|c|c|c|}
\hline Polymer sample & $f_{c}^{\text {WAXS }}$ & $T_{m}^{\mathrm{WAXS}}\left({ }^{\circ} \mathrm{C}\right)$ & $L(\mathrm{~nm})$ & $l_{c}(\mathrm{~nm})$ & $f_{\mathrm{cm}}^{\mathrm{DSC}}$ & $T_{m}^{\mathrm{DSC}}\left({ }^{\circ} \mathrm{C}\right)$ & $T_{c}^{\mathrm{DSC}}\left({ }^{\circ} \mathrm{C}\right)$ & $T_{m}^{\mathrm{DSC}}$ \\
\hline HDPE & 0.51 & 133 & 32.5 & 16.6 & 0.53 & 132 & 117 & 0.56 \\
\hline HDPE/MCM-41(3) & 0.54 & 134 & 35.6 & 19.2 & 0.52 & 131 & 117 & 0.55 \\
\hline HDPE/MCM-41(4) & 0.55 & 134 & 37.1 & 20.4 & 0.53 & 133 & 117 & 0.54 \\
\hline HDPE/MCM-41(6) & 0.54 & 131 & 38.4 & 20.7 & 0.53 & 132 & 118 & 0.55 \\
\hline HDPE/MCM-41(14) & 0.54 & 131 & 39.7 & 21.4 & 0.55 & 132 & 119 & 0.49 \\
\hline HDPE/MCM-41(23) & 0.54 & 132 & - & - & 0.55 & 132 & 120 & 0.40 \\
\hline HDPE/MCM-41(28) & 0.53 & 131 & - & - & 0.51 & 132 & 121 & 0.34 \\
\hline
\end{tabular}

calculated from the SAXS data in the melting process and represented in the lower plot of Fig. 6. This invariant gives us an idea about the macroscopic electron density fluctuations, and different regions are observed in that plot. The first one at low temperature, up to around $50^{\circ} \mathrm{C}$, is related to the crystallites existing at ambient temperature after processing. Interestingly, a clear increase of the invariant occurs at the end of this region for the HDPE homopolymer and for the nanocomposites with low MCM-41 contents, up to a $6 \mathrm{wt} \%$. This behaviour is indicative that important recrystallisation processes are involved and crystallites are thickening, corroborating the variation of long spacing values. The final fluctuation region is that associated with the main melting peak at about $134{ }^{\circ} \mathrm{C}$. After this, the curve becomes flat in the molten state. However, for the nanocomposites with high MCM-41 contents, the recrystallisation processes are hindered and only take place from relatively high temperatures, starting at $90^{\circ} \mathrm{C}$ for $\mathrm{HDPE} / \mathrm{MCM}$ 41(14) and HDPE/MCM-41(23) nanocomposites, whereas the invariant is practically unchanged for HDPE/MCM-41(28) until the melting process occurs. This fact seems to be associated with the higher confinement of HDPE crystallites within the MCM-41 channels, as nanofiller content increases, due to the larger amount of polyethylene chains in their inside. These observations are in agreement with FTIR, MAXS and TEM data already reported [17], indicating that ethylene polymerisation indeed occurred inside the channels of MCM-41 material and that moreover MCM-41 particles are dispersed in the polyethylene matrix in a nanometric scale.

Based on the overall data it may be assumed that these nanocomposites consist in polyethylene chains incorporated inside the channels of the MCM-41 derivatives in addition to some others chains surrounding the nanofillers.

\subsection{Thermal characterisation}

Additional knowledge on the structure developed in these nanocomposites is obtained from their thermal properties. The upper plot in Fig. 7 shows the DSC first melting curves for all of specimens. In this plot, the intensity of the melting endotherm is lowered as the mesoporous MCM- 41 content increases. This fact is ascribed to the lower amount of polyethylene within the polymeric nanocomposite with increasing MCM-41 composition at a given constant weight. However, if enthalpy is normalised taking into account the real amount of HDPE in the nanocomposites, the values obtained are now rather similar for neat HDPE and for the nanocomposites, as reported in Table 2 . On the other hand, the DSC melting temperatures are practically unchanged in the 


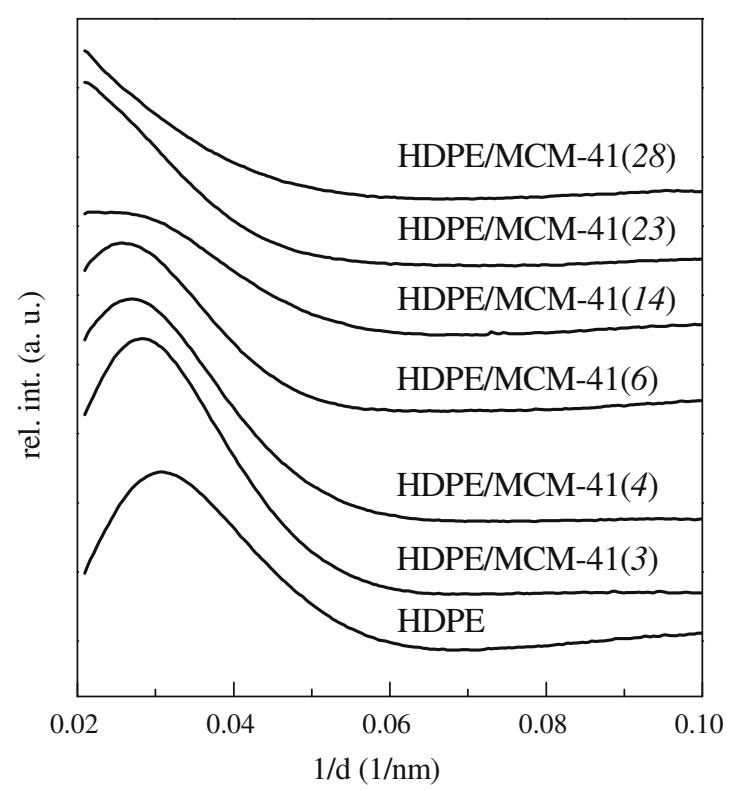

Fig. 4. SAXS diffraction patterns at room temperature for the HDPE homopolymer and the different nanocomposites.

different nanocomposites by comparison with that found in HDPE. Accordingly, no significant change on the molecular weight are expected for the nanocomposites when compared with this parameter in the HDPE produced under homogeneous conditions $\left(M_{w}=4 \times 10^{5} \mathrm{~g} / \mathrm{mol}\right)$. Melting temperatures estimated from DSC results are also in good agreement with data derived from the WAXS real-time measurements.

The crystallisation characteristics found for the different specimens are depicted in the bottom half of Fig. 7. The intensity of the exotherm considerably decreases with the incorporation of MCM-41 that involves a significant reduction of crystallinity after normalisation. Moreover, a slight increase in crystallisation temperature is observed for the nanocomposites with higher MCM-41 contents. This behaviour points out that crystallisation is delayed by the presence of the inorganic mesoporous solid. These results suggest that the crystallisation of intercalated HDPE located within MCM-41 channels in the nanocomposites is extremely hindered because of its confinement, leading to the delay of the crystallisation. Consequently, the amount of crystallites formed during the cooling run at $10{ }^{\circ} \mathrm{C} / \mathrm{min}$ for these nanocomposites with high MCM-41 contents is significantly smaller than for neat HDPE or for the nanocomposites with lower filler incorporations. If the nanocomposites remain enough time at room temperature (several hours), crystallisation of all the polyethylene chains ends and the number of crystal entities increases up to attain a final similar crystallinity, as discussed from the WAXS and DSC first melting results. On the other hand, it is found that the solid mesoporous MCM-41 seems to act as nucleant agent for those macrochains that surround the nanofiller and, accordingly, crystallisation temperature is slightly shifted to higher temperatures as its content is raised.

Changes in the crystallisation of the polyolefinic matrix in similar nanocomposites were also reported by other researchers. Kaminsky et al. prepared polypropylene/carbon nanotube (CNT) nanocomposites by in situ polymerisation. DSC analysis showed that neither melting point $\left(160 \pm 1^{\circ} \mathrm{C}\right)$ nor crystallinity degree of nascent polypropylene $(0.45 \pm 4 \%)$ was greatly influenced by the presence of the CNT filler, or by its concentration. But the temperatures of crystallisation from the melt rose with the concentration of CNT presented in the PP matrix. Moreover, the half-time of crystallisation was shortened in presence of the CNT, thus pointing out its effect as nucleating agent, causing the fast crystallisation of the surrounding polymer [24-26]. Nakajima et al. investigated PP/TiMCM-41 nanocomposites prepared by in situ polymerisation [27]. After removal of polypropylene formed in the outside of
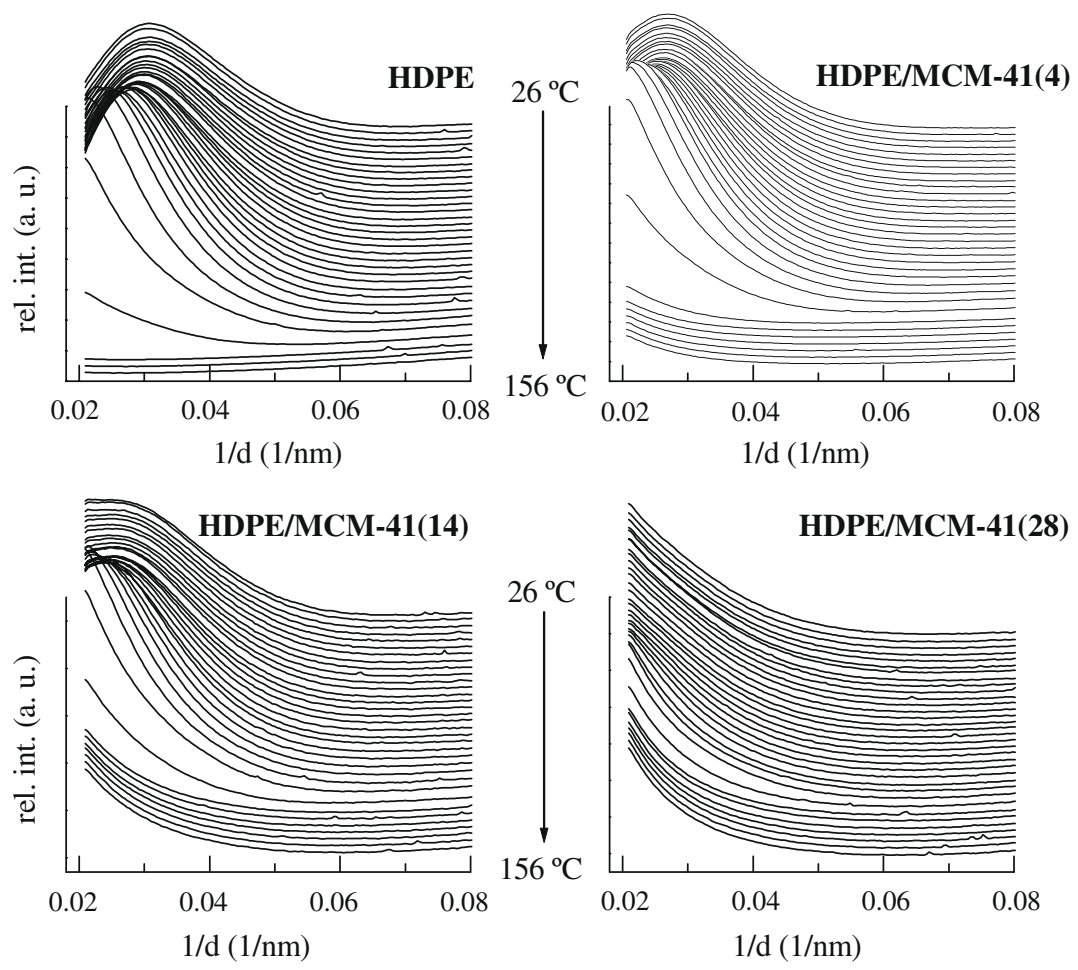

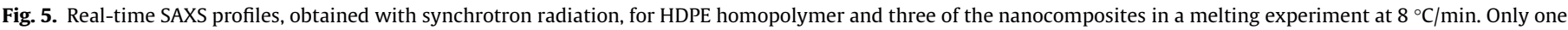
frame every three is plotted, for clarity. 

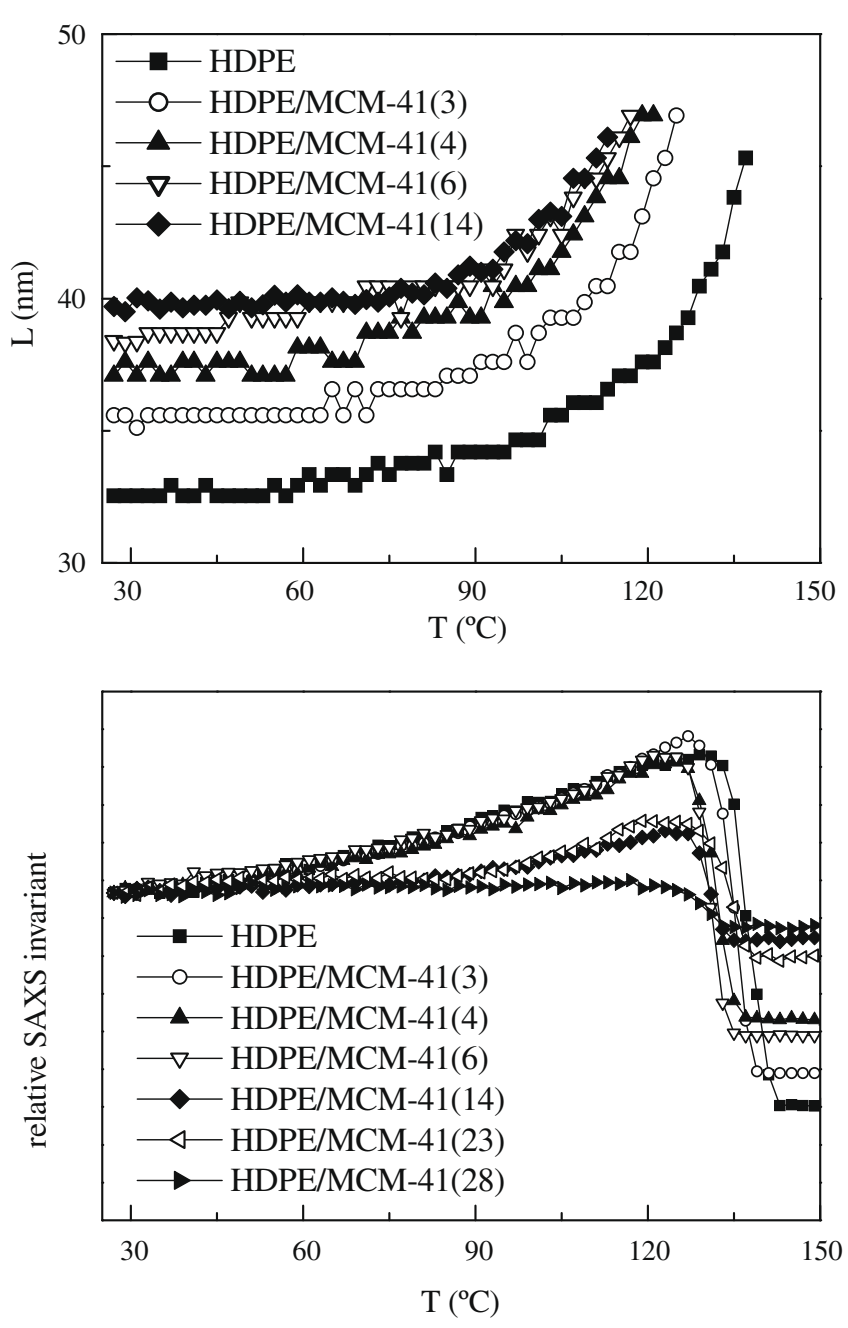

Fig. 6. Representation of the temperature dependence of the long spacing ( $L$, upper plot) and relative SAXS invariant (lower plot) for the HDPE homopolymer and the different nanocomposites.

Ti-MCM-41 particles (by extraction with boiling xylene), the DSC analysis of the polymer remaining inside the mesoporous material did not show a melting point. But after the alkaline dissolution of the mesoporous material, the melting of PP was visible in the DSC thermogram. This experiment demonstrates that the crystallisation of nascent PP formed inside the pores of Ti-MCM-41 was prevented, due to the restrictions imposed to polymer chain mobility by confinement within MCM-41 [27].

Other interesting aspect of these nanocomposites is related to the results obtained from thermogravimetry, as seen in Fig. 8. The onset of the degradation is faster and shifted to lower temperatures as MCM-41 content increases. The degradation temperature detected for HDPE is $483^{\circ} \mathrm{C}$. For nanocomposites with low filler contents, this temperature is decreased by around $40{ }^{\circ} \mathrm{C}$, whereas for the material with $28 \%$ filler contents this difference is around $160{ }^{\circ} \mathrm{C}$. Moreover, the derivative curves, depicted in the bottom plot of Fig. 8, show that the degradation process takes place in a unique stage for the neat polymeric matrix and for the nanocomposites with low MCM-41 contents. However, as the content of mesoporous filler increases, an overlapping of two stages becomes apparent, one probably related to the fraction of polymer inside the channels and the other to the fraction which surrounds the filler particles. Based on the amounts of filler used and the relative intensities of the peaks in the derivative curves, one can tentatively
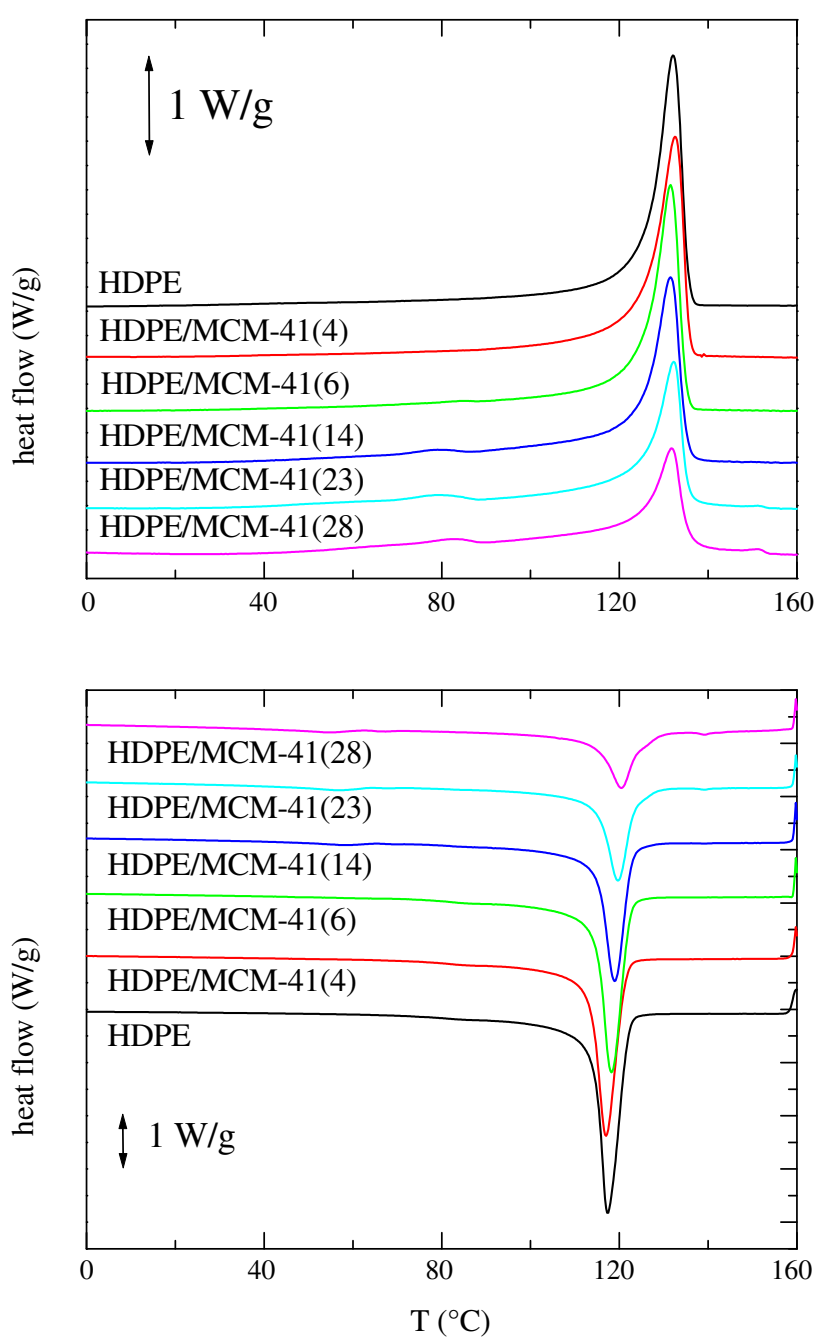

Fig. 7. DSC first melting curves (upper plot) and cooling curves (lower plot) for HDPE homopolymer and the nanocomposites, at $10^{\circ} \mathrm{C} / \mathrm{min}$.

assign the lower temperature degradation stage to the fraction of polyethylene located within the filler pores. All these features can be ascribed to a catalytic effect of MCM-41 in the degradation process of PE. While the catalytic effect of the inorganic material in the decomposition of polymers was also observed with several zeolites [16,28,29], MCM-41 materials appear to be more active in this process, probably due to their larger pore diameters [30]. These results suggest that the recycling of the nanocomposites at the end of their lifetime service, by reutilisation in chemical processes or in the production of liquid fuels, would be more favourable $[14,31]$.

\subsection{Viscoelastic behaviour and microhardness measurements}

Fig. 9 shows the variation of the storage and loss moduli and of the loss tangent for the different nanocomposites. In the upper plot, an increase of the storage modulus is observed as MCM-41 content rises. As discussed above, crystallinity is rather similar in the different specimens whereas crystal thickness increases with MCM-41 contents. Therefore, the stiffness is enlarged in the nanocomposites and this increase can be ascribed both to the larger size of crystallites and to the inherent reinforcement effect of mesoporous filler. However, this improvement of rigidity with MCM-41 contents is more important above room temperature that is, when the mobility within the olefinic polymer chains increases, as can be 


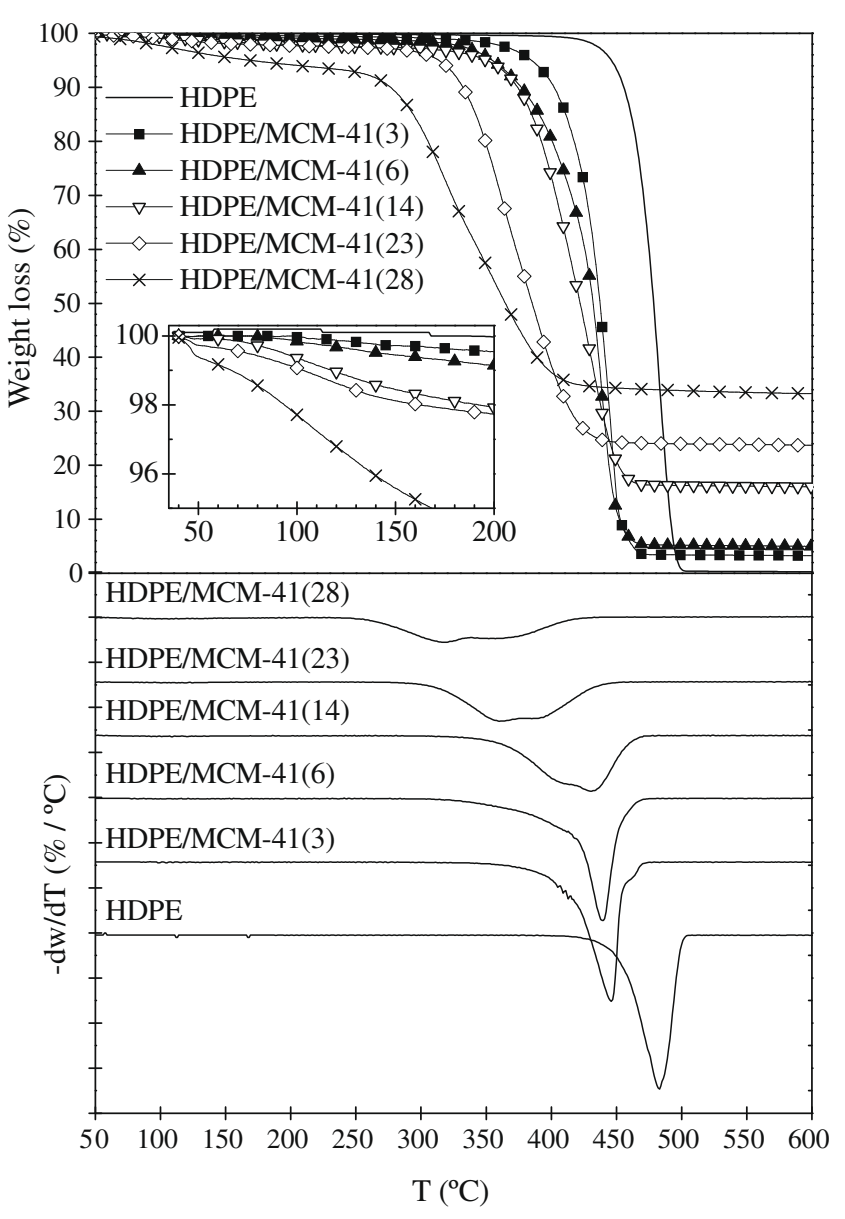

Fig. 8. TG (upper plot) and DTG curves (lower plot) for the different nanocomposites. DTG curves are vertically shifted, for clarity.

seen in Fig. 10. This fact is rather interesting from a practical point of view, since these materials will show an improved mechanical performance, by comparison with virgin HDPE, with no variation of the final processing temperature (as seem before, $T_{m}$ remains practically constant for all specimens).

The increase in stiffness with MCM-41 contents was apparent also from the microhardness values, $\mathrm{MH}$, as listed in Table 4 . Microhardness measures primarily the resistance of the material to plastic deformation and, accordingly, provides indications regarding local strain. A relationship is commonly found between the elastic modulus and $\mathrm{MH}$ and the following empirical equation has been proposed [20]:

$\mathrm{MH}=a \cdot E^{b}$

where $\mathrm{MH}$ is the microhardness value, $E$ is the elastic modulus and $a$ and $b$ are constants. A linear double-logarithmic dependence between these two magnitudes allows, once the behaviour has been established for a set of materials, the reliable estimation of the elastic modulus in unknown specimens by a relatively rapid measurement as microhardness without requiring a large amount of material. However, Fig. 11 shows that the correlation between the two mechanical parameters in the nanocomposites is more complex than usual, and several regions are distinguishable in the plot. In HDPE and HDPE/MCM-41( $x$ ) nanocomposites with low MCM-41 incorporation, the increase in rigidity might be associated mainly with the increase in crystallite thickness. At intermediate contents, the increase in stiffness may be attributed to a combination of larger crystals and mesoporous MCM-41 reinforcement effect,

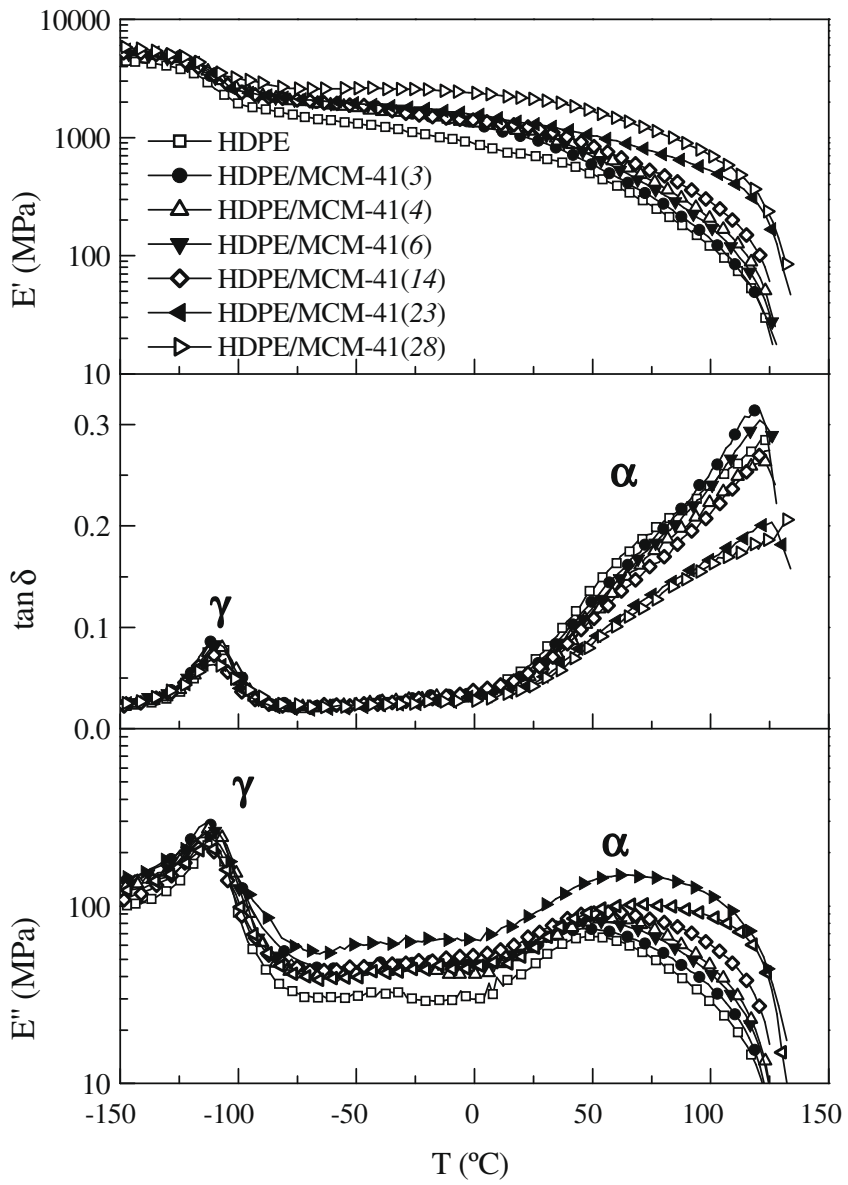

Fig. 9. Temperature dependence of the real $\left(E^{\prime}\right)$ and imaginary $\left(E^{\prime \prime}\right)$ components of complex modulus and of the loss tangent $(\tan \delta)$ for the different samples.

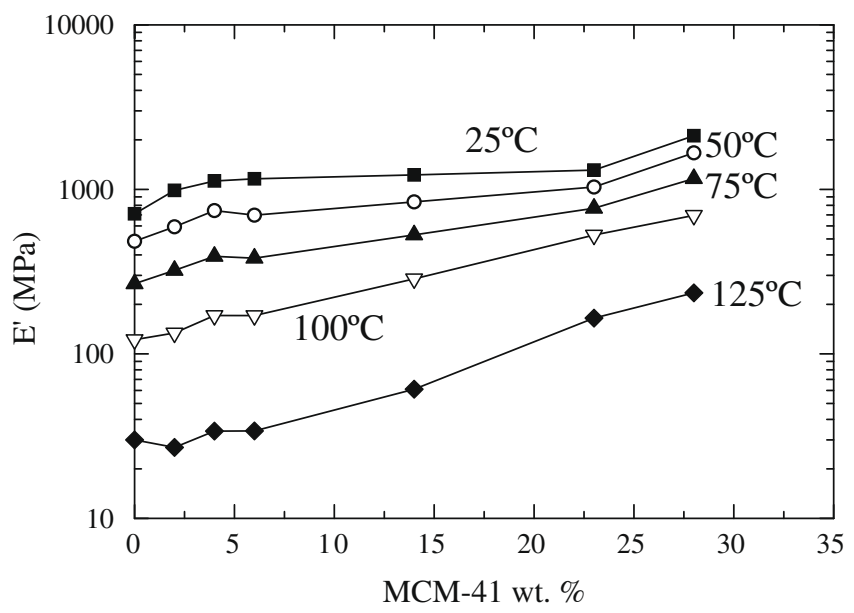

Fig. 10. Variation of the storage modulus $\left(E^{\prime}\right)$ at the indicated temperatures as a function of MCM-41 content.

whereas for HDPE/MCM-41(28) the jump in stiffness should be mainly related to the latter effect, due to the large content of a hard inorganic component. A complex relationship between these two mechanical properties has been also observed in other composite materials [32].

In relation to relaxation processes, the loss plots $\left(\tan \delta\right.$ and $E^{\prime \prime}$ representations in Fig. 9) show the existence of two main processes, labelled as $\gamma$ and $\alpha$ in order of increasing temperatures, 
Table 4

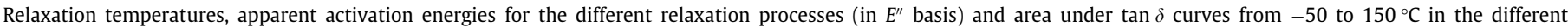
nanocomposites at $3 \mathrm{~Hz}$ as well as microhardness values at $23^{\circ} \mathrm{C}$.

\begin{tabular}{|c|c|c|c|c|c|c|}
\hline \multirow[t]{2}{*}{ Polymer sample } & \multicolumn{2}{|l|}{$T\left({ }^{\circ} \mathrm{C}\right)$} & \multicolumn{2}{|c|}{$\Delta H(\mathrm{~kJ} / \mathrm{mol})$} & \multirow[t]{2}{*}{$\operatorname{Tan} \delta$ area (a.u.) } & \multirow[t]{2}{*}{$\mathrm{MH}(\mathrm{MPa})$} \\
\hline & $\gamma$ & $\alpha$ & $\gamma$ & $\alpha$ & & \\
\hline HDPE & -112 & 51 & 155 & 200 & 22 & 29 \\
\hline HDPE/MCM-41(3) & -112 & 50 & 145 & 180 & 22 & 32 \\
\hline HDPE/MCM-41(4) & -112 & 50 & 145 & 180 & 20 & 33 \\
\hline HDPE/MCM-41(6) & -112 & 51 & 140 & 150 & 21 & 34 \\
\hline HDPE/MCM-41(14) & -113 & 56 & 130 & 150 & 19 & 39 \\
\hline HDPE/MCM-41(23) & -113 & 63 & 130 & 150 & 17 & 47 \\
\hline HDPE/MCM-41(28) & -114 & 64 & 130 & 150 & 16 & 86 \\
\hline
\end{tabular}

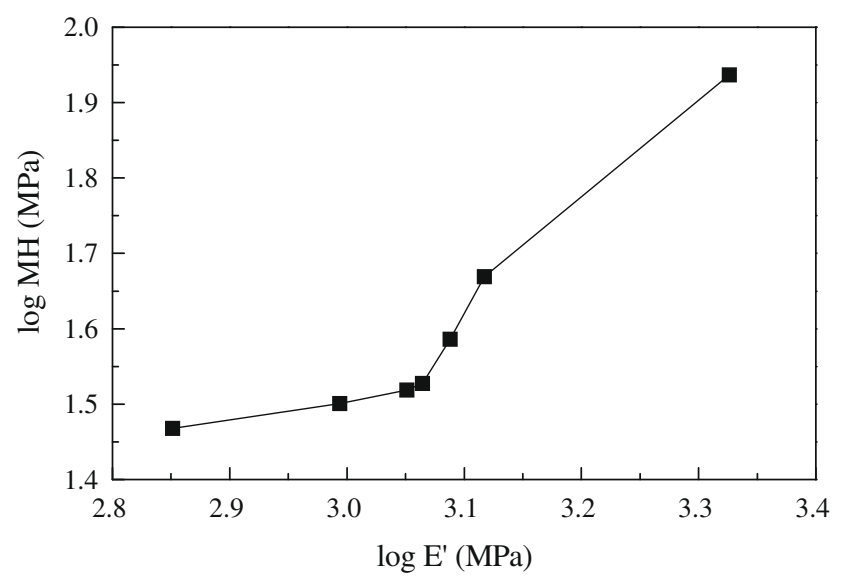

Fig. 11. Relationship between microhardness $(\mathrm{MH})$ and elastic modulus $\left(E^{\prime}\right)$ for the different samples.

whose intensity and location is slightly dependent on MCM-41 content. The other known relaxation, commonly named as $\beta$ and located between the $\gamma$ and the $\alpha$ processes in low density, linear low density, and ethylene copolymers, is not clearly observed for these specimens [33,34]. The crystallinity of these samples is relatively high and, therefore, this relaxation process is almost absent and overlapped with the $\alpha$ mechanism, corroborating similar features found in other HDPE samples [35].

The $\gamma$ relaxation in polyethylene was firstly attributed to crankshaft movements of polymethylenic chains [36]. However, there is no clear consensus regarding the details of the underlying motional process [37]. This type of motion requires chains containing sequences of three or more methylenic units. Fig. 9 and data in Table 4 show that the location of $\gamma$ loss modulus peak is practically unaffected with MCM-41 content, but its intensity decreases. As the motions ascribed to this relaxation process take place in the amorphous regions, they are in principle hindered as mesoporous material content increases, due to the crystallite thickening and to the confinement effect of the nanofiller, which introduces mobility constraints.

The relaxation that appears at higher temperature and is better defined in $E^{\prime \prime}$ plots for polyethylene, $\alpha$ relaxation, has been associated with vibrational and reorientational motions within the crystallites $[38,39]$. At the highest temperatures, the melting of the crystallites is overlapped with the this relaxation process As discussed for the motions within the amorphous regions, those occurring in the crystals also become more restricted as the MCM-41 contents increases, and consequently the location of the $\alpha$ relaxation is shifted to higher temperatures and its intensity is considerably reduced.

Additional information on mechanical performance of these hybrid materials can be attained from these loss magnitudes since they are related to viscoelastic energy dissipation, which is expected to make a significant contribution in the impact energy because the time scale involved in impact deformation is of comparable order of magnitude as the relaxation time of viscoelastic processes. Therefore, correlation of impact strength with dynamic mechanical behaviour has been previously reported [40-44]. The area under the loss tangent curve provides an estimation of the impact strength, although it is not a direct measurement. In the present investigation, the region integrated has been that from -50 to $150{ }^{\circ} \mathrm{C}$ and the values obtained are listed in the penultimate column of Table 4 . As expected, a decrease of area is observed, indicating that the nanocomposites are able to absorb less energy before breaking, as MCM-41 content increases. However, it is noticeable that this reduction is much smaller than the increase in microhardness or elastic modulus fact that seems to point out that a favourable compromise between these two opposite mechanical characteristics is reached.

\section{Conclusions}

The use of mesoporous MCM-41 as catalyst carrier and as nanofiller is an effective route for the successful preparation of nanocomposites by in situ supported ethylene polymerisation. Structural characterisation of nanocomposites shows minimal changes in crystallinity. However, crystallites become thicker as the MCM-41 content is raised in the nanocomposites. A delay in the crystallisation process is observed from DSC data, pointing out to a confinement effect of the macrochains within pores and channels of MCM-41 particles. In addition, these novel self-reinforced nanocomposites present an increase in rigidity, which becomes more important as temperature is raised. Accordingly, they exhibit an improved mechanical performance without varying the final processing temperature since $T_{m}$ is the same for all of the specimens. This feature is an aspect rather attractive from a practical standpoint. These nanocomposites are also characterised by an easier degradability because of the additional role of mesoporous MCM-41 as promoter for PE degradation. Therefore, their use may lead to cheaper, lighter, environmentally friendly and more resistant materials.

\section{Acknowledgments}

Financial support of Ministerio de Educación y Ciencia (project MAT2007 65519-C02-01), Exchange Collaboration Program CSIC/ GRICES (projects 2005PT0033 and Proc. 4-1-1 Espanha 2006/2007, respectively), and Fundação para a Ciência e a Tecnologia (FCT), (Projecto PDCT/CTM/66408/2006) is acknowledged. J.M.C. thanks the FCT for his PhD scholarship (ref. SFRH/BD/16547/2004). The synchrotron work was supported by the European Community - Research Infrastructure Action under the FP6 "Structuring the European Research Area" Programme (through the Integrated Infrastructure Initiative "Integrating Activity on Synchrotron and Free 
Electron Laser Science"), contract RII3-CT-2004-506008 (IA-SFS). We thank the collaboration of the Hasylab personnel in the soft-condensed matter beamline A2, especially Dr. S.S. Funari.

\section{References}

[1] C. Gonzalez-Arellano, A. Corma, M. Iglesias, F. Sanchez, Eur. J. Inorg. Chem. 7 (2008) 1107.

[2] M. Guidotti, C. Pirovano, N. Ravasio, B. Lazaro, J.M. Fraile, J.A. Mayoral, B. Coq, A Galarneau, Green Chem. 11 (2009) 1421.

[3] N. Candu, S. Coman, V.I. Parvulescu, J. El Haskouri, P. Amoros, D. Beltran, Top. Catal. 52 (2009) 571.

[4] V. Meynen, P. Cool, E.F. Vansant, Micropor. Mesopor. Mater. 125 (2009) 170.

[5] H. Rahiala, I. Beurroies, T. Eklund, K. Hakala, R. Gougeon, P. Trens, J.B. Rosenholm, J. Catal. 188 (1999) 14.

[6] R.R. Rao, B.M. Weckhuysen, R.A. Schoonheydt, Chem. Commun. 5 (1999) 445

[7] Y.S. Ko, Macromol. Chem. Phys. 202 (2001) 739.

[8] T. Sano, Y. Oumi, Catal. Surveys From Asia 8 (2004) 295.

[9] J.M. Campos, M.R. Ribeiro, J.P. Lourenco, A. Fernandes, J. Mol. Catal. A-Chem. 277 (2007) 93.

[10] C. Alonso-Moreno, D. Pérez-Quintanilla, D. Polo-Ceron, S. Prashar, I. Sierra, I. del Hierro, M. Fajardo, J. Mol. Catal. A-Chem. 304 (2009) 107.

[11] G. Calleja, J. Aguado, A. Carrero, J. Moreno, Catal. Commun. 6 (2005) 153

[12] G. Calleja, J. Aguado, A. Carrero, J. Moreno, Appl. Catal. A-Gen. 316 (2007) 22

[13] G. Kickelbick, Prog. Polym. Sci. 28 (2003) 83.

[14] J. Aguado, D.P. Serrano, M.D. Romero, J.M. Escola, Chem. Commun. 6 (1996) 725

[15] A. Marcilla, A. Gomez, A.N. Garcia, M.M. Olaya, J. Anal. Appl. Pyrol. 64 (2002) 85.

[16] F.S.M. Sinfronio, A.G. Souza, I.M.G. Santos, V.J. Fernandes, C. Novak, Z. Ehen, J. Therm. Anal. Calorim. 85 (2006) 391.

[17] J.M. Campos, J.P. Lourenco, E. Pérez, M.L. Cerrada, M.R. Ribeiro, J. Nanosci. Nanotechnol. 9 (2009) 3966.

[18] F.A. Quinn, L. Mandelkern, J. Am. Chem. Soc. 80 (1958) 3178.

[19] B. Wunderlich, Macromolecular Physics, Academic Press, New York, 1980.
[20] F.J.B. Calleja, Adv. Polym. Sci. 66 (1985) 117.

[21] K. Shirayam, H. Watabe, S. Kita, Makromol. Chem. 151 (1972) 97.

[22] C.W. Bunn, Trans. Faraday Soc. 40 (1944) 23.

[23] A.J. Ryan, J.L. Stanford, W. Bras, T.M.W. Nye, Polymer 38 (1997) 759.

[24] W. Kaminsky, A. Funck, C. Klinke, Top. Catal. 48 (2008) 84.

[25] W. Kaminsky, A. Funck, K. Wiemann, Macromol. Symp. 239 (2006) 1.

[26] K. Wiemann, W. Kaminsky, F.H. Gojny, K. Schulte, Macromol. Chem. Phys. 206 (2005) 1472

[27] H. Nakajima, K. Yamada, Y. Iseki, S. Hosoda, A. Hanai, Y. Oumi, T. Teranish, T. Sano, J. Polym. Sci. Part B-Polym. Phys. 41 (2003) 3324.

[28] J. Aguado, D.P. Serrano, J.M. Escola, E. Garagorri, J.A. Fernandez, Polym. Degrad. Stabil. 69 (2000) 11.

[29] A. Marcilla, A. Gomez, S. Menargues, Polym. Degrad. Stabil. 89 (2005) 454

[30] A. Marcilla, A. Gomez-Siurana, D. Berenguer, Appl. Catal. A-Gen. 301 (2006) 222.

[31] S. Chaianansutcharit, R. Katsutath, A. Chaisuwan, T. Bhaskar, A. Nigo, A. Muto, Y. Sakata, J. Anal. Appl. Pyrol. 80 (2007) 360.

[32] M.L. Cerrada, R. Benavente, E. Pérez, Macromol. Chem. Phys. 202 (2001) 2686.

[33] R. Popli, M. Glotin, L. Mandelkern, R.S. Benson, J. Polym. Sci., Part B-Polym. Phys. 22 (1984) 407

[34] R. Popli, L. Mandelkern, Polym. Bull. 9 (1983) 260.

[35] M.L. Cerrada, R. Benavente, B. Peña, E. Pérez, Polymer 41 (2000) 5957.

[36] T.F. Schatzki, J. Polym. Sci. 57 (1962) 337.

[37] R.H. Boyd, Polymer 26 (1985) 1123.

[38] I.M. Ward, Mechanical Properties of Solid Polymers, second ed., John Wiley and Sons, Chichester, 1983.

[39] N. McCrum, B. Read, G. Williams, Anelastic and Dielectric Effects in Polymeric Solids, Dover Publications, New York, 1991.

[40] P.I. Vincent, Polymer 1 (1960) 425.

[41] J.J. Heijboer, J. Polym. Sci., Part C: Polym. Phys. 16 (1967) 3755.

[42] A. Hiltner, E. Baer, Polymer 15 (1974) 1405.

[43] S.H. Jafari, A.K. Gupta, J. Appl. Polym. Sci. 78 (2000) 962.

[44] O. Prieto, J.M. Pereña, R. Benavente, E. Pérez, M.L. Cerrada, J. Polym. Sci. Polym. Phys. 41 (2003) 1878. 